\title{
Evaluation of the Elastic-Plastic Mixity Parameters on the Base of Different Crack Propagation Criteria. Part 1. Preliminary Analysis
}

\author{
V. N. Shlyannikov and Zh. M. Sakhabutdinov \\ Kazan State Power Engineering University, Kazan, Russia
}

УДК 539.4

\section{Оценка упругопластического параметра смешанности на основе различных критериев роста трещины. Сообщение 1. Предвари- тельный анализ}

\section{В. Н. Шлянников, Ж. М. Сахабутдинов}

Казанский государственный энергетический университет, Казань, Россия

Исходя из рассмотрения доминирующего механизма разруиения для оченки поведения материала при маломаситабной текучести в области вериины трецины сформулировань асимптотические управляющие уравнения и их граничные условия для случаев плоской деформации и плоского напряженного состояния. Уравнения основаны на деформационной теории пластичности со степенньил упрочнением. Анализ близлежащих полей напряжений выполнен для критериев максимальньх нормальных и касательньх напряжений, полного диапазона смешанных форм деформирования и различныхх уровней показателя упрочнения. Предложена новая схема решения задач смешанных форм разруиения. Установленныле соотношения между определяющили упрусими и пластическими паралетрами смешанности представлены как функиии вида критерия роста трецины и показателя деформаицонного упрочнения материала.

Ключевые слова: поведение трещин при смешанном типе деформирования, маломасштабная текучесть, смена механизма разрушения, рост трещины, параметры смешанности.

Introduction. Fatigue crack growth can be controlled by a mixture of processes (ductile and brittle), mechanisms (static, fatigue, creep) and loading modes (tension, torsion, biaxial/multiaxial) [1]. Additionally, mixed-mode crackextension can be affected by many other considerations such as artefact geometry (thin plates, thick shells, and the size, shape and orientation of the defect), environmental effects (temperature, gaseous and liquid environment), material state (crystallographic structure, heat treatment and route of manufacture), and stress conditions (out-of-phase and random loading effects).

One of the important issues is that, for a large number of known mixed-mode crack growth problems there are two fundamentally distinct classes of growth: maximum principal stress-dominated and shear-dominated ones. This is true regardless of whether we consider static or cyclic loading conditions. Another issue is the intimate connection of the crack tip displacement concept to mixed-mode elastic-plastic fracture and fatigue processes. Several elastic-plastic finite element analyses [2-13] showed non-uniform deformation and damage fields near an initially smooth notch tip under mixed mode loading. 
Aoki et al. [2] predicted that two competing process zones may be associated with the tip of crack; one process zone dominated by tensile stress and the other one dominated by shear stress. The side of the notch, dominated by tensile stress, blunts, while the other side, dominated by shear strains, sharpens. It was shown in [10] and [14] that the stable crack under mixed-mode loading conditions propagates either as a Mode I crack approximately in the direction normal to the maximum tangential stresses (that is referred as "tensile crack") or as a Mode II crack in the maximum shear strain direction (that is referred as "shear crack"). It is clear from the preceding discussion that there are two competing fracture mechanisms that are operative near the sharpened and blunted part of the notch, respectively, in a ductile material under mixed-mode loading. The dominant mechanism (between the two considered) establishes the stable crack growth direction. Furthermore, under mixed-mode loading crack growth would no longer take place in self similar manner, that is, it will grow along a curvilinear path. The principal feature of such crack growth is that the stable crack propagates either as dominating by tensile crack fracture mechanism approximately in the direction normal to the maximum tangential stresses or as dominated by shear crack fracture mechanism in the maximum strain direction.

Several analytical and numerical studies have been undertaken to analyze stress-strain state at the tip in order to understand elastic-plastic mixed-mode crack behavior. For example, Shih [15] has examined the line crack subjected to combined Mode I and Mode II loading using a "small-scale yielding" analysis of an elastic-plastic body under plane strain conditions (i.e., extending the HRRsolution [16, 17] on Mode I fracture to the mixed mode case). Shih [15] has shown that two parameters, the $J$-integral and the mixity parameter $M_{P}$, completely define the near-tip asymptotic stress field. The analysis was only related to the plane strain tensile crack fracture mechanism (boundary conditions) for small scale yielding. In [15], the plane stress crack behavior and the fracture mechanism associated with shear crack were not taken into consideration.

All the above analytical and numerical analyses on the effect of the dominant fracture mechanism under mixed-mode loading are focused on Mode I boundary conditions. A similar investigation for both tensile and shear cracks in elasticplastic solids has not been carried out in the past. In the present paper, a steady-state crack in elastic-plastic solids is simulated using a dominant singularity solution governing the asymptotic behavior at the crack tip. Our investigation is carried out within the framework of mixed-mode (combining Mode I and Mode II), both plane strain and plane stress, and small scale yielding conditions.

Most of the developed theories concerning the mechanisms of fracture are based naturally on microscopic structure of materials. The theories dealing primarily with the mechanism of ductile fracture implicate the influence of the voids, creating at the core region around the crack tip, on the mode of initiation and propagation of a crack. The macroscopic effect of this mechanism of nucleation, growth and coalescence of voids is an increment of crack length in direction of initial crack propagation $\theta^{*}$, which is apparent in various degrees in all materials from the quasi-brittle to the quasi-plastic. The simultaneous presence of yielding and fracture implies that several failure mechanisms are interfering in 
fracture of ductile materials, and the zone of influence of these mechanisms is quite extended. Since it includes a plastic zone around the crack tip and an elastic layer adjacent to it containing the voids. These zones may be large or insignificant, depending on the particular properties of the material.

In brittle or quasi-brittle materials, the plastic zone developed before the final fracture remains rather small with respect to the crack length and therefore linear elastic fracture mechanics theory yields satisfactory results. Ductile materials under plane strain and plane stress conditions also respond in small scale yielding fracture as those for example, which exhibit a discontinuous mode of fracture in which some of the grains cleave ahead of the main crack, and the bridging regions between them then break in a ductile manner, and for which the extent of the plastic zones may also be very limited. Then for this type of fracture, the singular elastic solution may also be considered as a true representation of the stress and strain fields outside the plastic zone.

Elastic Stress-Strain State. Let us consider a crack in a general mixedmode stress field and examine the extension of the crack from the tip. All the geometric configurations, characterizing the loaded cracked plate as well as the stress field, are shown in Fig. 1.

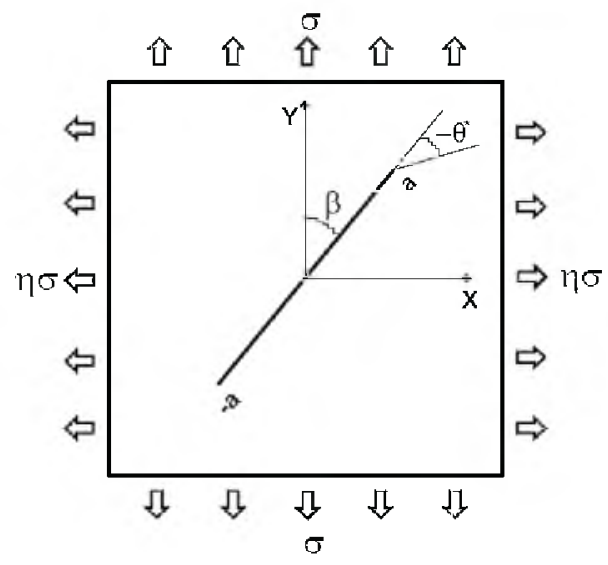

Fig. 1. The biaxially loaded inclined crack and the direction $\theta^{*}$ of propagation.

For an elastic and isotropic plate, under conditions of plane strain, containing an inclined internal crack of length $2 a$ and obliqueness $\beta$, which is submitted at infinity to a biaxial stressed state, defined by the stress $\sigma_{y n}=\sigma$ and $\sigma_{x n}=\eta \sigma$ along two adjacent sides of the plate, the components of stresses at the tip crack are given by relations [18-20]

$$
\left\{\begin{array}{l}
\sigma_{x x}=\frac{K_{1}}{\sqrt{2 \pi r}} \cos \frac{\theta}{2}\left(1-\sin \frac{\theta}{2} \sin \frac{3 \theta}{2}\right)-\frac{K_{2}}{\sqrt{2 \pi r}} \sin \frac{\theta}{2}\left(2+\cos \frac{\theta}{2} \cos \frac{3 \theta}{2}\right)+T, \\
\sigma_{y y}=\frac{K_{1}}{\sqrt{2 \pi r}} \cos \frac{\theta}{2}\left(1+\sin \frac{\theta}{2} \sin \frac{3 \theta}{2}\right)+\frac{K_{2}}{\sqrt{2 \pi r}} \sin \frac{\theta}{2} \cos \frac{\theta}{2} \cos \frac{3 \theta}{2} \\
\sigma_{x y}=\frac{K_{1}}{\sqrt{2 \pi r}} \sin \frac{\theta}{2} \cos \frac{\theta}{2} \cos \frac{3 \theta}{2}+\frac{K_{2}}{\sqrt{2 \pi r}} \cos \frac{\theta}{2}\left(1-\sin \frac{\theta}{2} \sin \frac{3 \theta}{2}\right)
\end{array}\right.
$$


where the stress intensity factors $K_{1}$ and $K_{2}$ as well as the nonsingular term $T$ are given by

$$
\begin{gathered}
K_{1}=\frac{\sigma \sqrt{\pi a}}{2}[1+\eta-(1-\eta) \cos 2 \beta], \quad K_{2}=\frac{\sigma \sqrt{\pi a}}{2}(1-\eta) \sin 2 \beta, \\
T=\sigma(1-\eta) \cos 2 \beta .
\end{gathered}
$$

In these relations, $\eta$ is the biaxiality factor of the stresses $\sigma_{y n}$ and $\sigma_{x n}$ at infinity, $\eta=\sigma_{x n} / \sigma_{y n}$, and $\beta$ is the angle subtended by the axis of loading and the crack plane, $\mathrm{a}$ is the half of the crack length. The crack orientation angle $\beta$ (Fig. 1) is measured positive clockwise and is reckoned from vertical direction or the direction of major tension. For the case of the oblique crack, the crack-field mode mixity parameter $M_{E}$ expressed by relation (1) and (2), is given by

$$
M_{E}=\frac{2}{\pi} \tan ^{-1}\left|\lim _{r \rightarrow \infty} \frac{\sigma_{\theta \theta}(\theta=0)}{\sigma_{r \theta}(\theta=0)}\right|=\frac{2}{\pi} \tan ^{-1}\left|\frac{K_{1}}{K_{2}}\right|=\frac{2}{\pi} \tan ^{-1}\left|\frac{1+\eta-(1-\eta) \cos 2 \beta}{(1-\eta) \sin 2 \beta}\right| .
$$

A number of criteria is available for the prediction of direction of the initial crack extension $\theta^{*}$. All these are defined using either some aspects of the stress-strain field existing prior to the start of propagation or some modification thereof occurring as a consequence of the extension. The criteria belonging to the first category are the prior stress field criteria. The local symmetry criterion [21, 22] belongs to the second group and the predictions of $\theta^{*}$ are based on changes in the crack tip stress-strain field arising out of an infinitesimal extension of the main crack. This criterion predicts the extension in the direction given by either $F_{2}=0$ (where $F_{2}$ is the crack extension force at the tip normal to its own plane), or $K_{2}$ (where $K_{2}$ is the Mode II stress intensity factor at the tip of a propagating crack). Note that for an inclined crack under remote uniform biaxial tension, the prediction based on the local symmetry criterion is close to those due to some of the prior field criteria [23, 24]). The present paper deals with an application of the maximum tangential stress and the maximum shear stress criteria, because, as it is clear from above discussion, they are corresponding to the two main dominant fracture mechanisms. The criteria of maximum tangential stress and the maximum shear stress are the examples of the prior stress field criteria. They directly use certain functions of stress or strain components in an element ahead of the crack tip to specify the basis for the determination of fracture angle $\theta^{*}$. In all cases, the crack is considered to extend in the radial direction for which the basis function has an extremum, and the propagation begins when the function reaches a critical value.

In the case of the maximum tangential stress (MTS) criterion [23], the crack is considered to extend from the crack tip in the radial direction given by the point of maximum tangential stress on a circle of finite radius from the point of fracture initiation. The crack propagation angle $\theta^{*}$ is measured negative clockwise from the crack axis and passing through the point of fracture initiation. 
In the case of the maximum shear stress (MSS) criterion [24, 25], the initial extension occurs along the plane of the maximum shear stress around the crack tip. Both MTS and MSS criteria were further used by Williams and Ewing [26], Eftis et al. [20] and Chrysakis [24, 25] who incorporated in the analysis the second (non-singular) term in the series expansion of the crack tip stress field. This idea improved considerably the fit of the theoretical predictions to the experimental data.

The mathematical formulation of the above criteria is expressed as follows.

The Maximum Tangential Stress Criterion. Let $r$ and $\theta$ denote the polar coordinates centered at the crack tip. Then, adopting the notation

$$
\begin{cases}F_{k 1}=1+\eta-(1-\eta) \cos 2 \beta, & F_{x 1}=\cos \frac{\theta}{2}\left(1-\sin \frac{\theta}{2} \sin \frac{3 \theta}{2}\right), \\ F_{k 2}=(1-\eta) \sin 2 \beta, & F_{x 2}=\sin \frac{\theta}{2}\left(2+\cos \frac{\theta}{2} \cos \frac{3 \theta}{2}\right), \\ F_{y 1}=\cos \frac{\theta}{2}\left(1+\sin \frac{\theta}{2} \sin \frac{3 \theta}{2}\right), & F_{x y 1}=\sin \frac{\theta}{2} \cos \frac{\theta}{2} \cos \frac{3 \theta}{2}, \\ F_{y 2}=\sin \frac{\theta}{2} \cos \frac{\theta}{2} \cos \frac{3 \theta}{2}, & F_{x y 2}=\cos \frac{\theta}{2}\left(1-\sin \frac{\theta}{2} \sin \frac{3 \theta}{2}\right), \\ F_{\theta 1}=3 \cos \frac{\theta}{2}+\cos \frac{3 \theta}{2}, & F_{\theta 2}=\sin \frac{\theta}{2}+\sin \frac{3 \theta}{2},\end{cases}
$$

it is for the biaxially loaded crack

$$
\begin{gathered}
\sigma_{\theta \theta}=\frac{K_{1}}{4 \sqrt{2 \pi r}}\left(3 \cos \frac{\theta}{2}+\cos \frac{3 \theta}{2}\right)-\frac{K_{2}}{4 \sqrt{2 \pi r}}\left(3 \sin \frac{\theta}{2}+3 \sin \frac{3 \theta}{2}\right)+ \\
+\sigma_{y n}(1-\eta) \cos 2 \beta \sin ^{2} \theta,
\end{gathered}
$$

or in dimensionless form

$$
\frac{\sigma_{\theta \theta}}{\sigma_{y n}}=\frac{1}{8 \sqrt{2}} \sqrt{a / r}\left[F_{k 1} F_{\theta 1}-3 F_{k 2} F_{\theta 2}\right]+T \sin ^{2} \theta .
$$

The derivative of $\bar{\sigma}_{\theta \theta}=\sigma_{\theta \theta} / \sigma_{y n}$ is

$$
\frac{d \bar{\sigma}_{\theta \theta}}{d \theta}=\frac{1}{8 \sqrt{2}} \sqrt{a / r}\left[F_{k 1} \frac{d F_{\theta 1}}{d \theta}-3 F_{k 2} \frac{d F_{\theta 2}}{d \theta}\right]+2 T \sin \theta \cos \theta .
$$

Now the maxima of $\bar{\sigma}_{\theta \theta}$ are determined by certain solutions of the equation

$$
\sqrt{a / r}\left[F_{k 1} F_{\theta 1}^{\prime}-3 F_{k 2} F_{\theta 2}^{\prime}\right]+16 \sqrt{2} T \sin \theta \cos \theta=0 .
$$

where $0^{\prime}=d / d \theta$. 
The Maximum Shear Stress Criterion. Similarly, from [19, 20]

$$
\left.\tau_{r \theta}^{2}\right|_{\max }=\frac{1}{4}\left(\sigma_{y y}-\sigma_{x x}\right)^{2}+\sigma_{x y}^{2}
$$

and taking into account Eqs. (1)-(4):

$$
\begin{gathered}
\left.\frac{\tau_{r \theta}}{\sigma_{y n}}\right|_{\max }=\left\{\frac{1}{4}\left\{\sqrt{\frac{a}{8 r}}\left[F_{k 1}\left(F_{y 1}-F_{x 1}\right)+F_{k 2}\left(F_{y 2}+F_{x 2}\right)\right]-T\right\}^{2}+\right. \\
\left.+\frac{a}{8 r}\left[F_{k 1} F_{x y 1}+F_{k 2} F_{x y 2}\right]^{2}\right\}^{1 / 2} .
\end{gathered}
$$

The equation $d \bar{\tau}_{r \theta} / d \theta\left(\bar{\tau}_{r \theta}=\tau_{r \theta} / \sigma_{y n}\right)$, after some algebra, takes the form

$$
\frac{P_{1}}{4}\left[F_{k 1}\left(F_{y 1}^{\prime}-F_{x 1}^{\prime}\right)+F_{k 2}\left(F_{y 2}^{\prime}+F_{x 2}^{\prime}\right)\right]+P_{2}\left[F_{k 1} F_{x y 1}^{\prime}+F_{k 2} F_{x y 2}^{\prime}\right]=0,
$$

where

and

$$
P_{1}=\sqrt{\frac{a}{8 r}}\left[F_{k 1}\left(F_{y 1}-F_{x 1}\right)+F_{k 2}\left(F_{y 2}+F_{x 2}\right)\right]-T
$$

$$
P_{2}=\frac{a}{8 r}\left[F_{k 1} F_{x y 1}+F_{k 2} F_{x y 2}\right]
$$

It is expedient to study the positions of the maxima for both criteria for different inclinations of the crack axis. These positions are defined by their angle $\theta^{*}$ subtended between the direction of the respective $\bar{\sigma}_{\theta \theta^{-}}$and $\bar{\tau}_{r \theta}$-maximum and the crack axis. In order to define angle of crack propagation $\theta^{*}$ we zero the first derivative [Eqs. (8) and (11), respectively], examining also the sign of its second derivative, that is

$$
\frac{d^{2} \bar{\sigma}_{\theta \theta}}{d \theta^{2}}<0 \quad \text { and } \quad \frac{d^{2} \bar{\tau}_{r \theta}}{d \theta^{2}}<0
$$

Both criteria (5) and (9) are based on singular solutions, the point of view being that the stress-strain characteristics are not determined at the crack tip itself, but at some distance $r$ from it. Sih [15] considered that this radius must be constant and greater than the radius of a so-called core region defined by the limits of continuum mechanics, or by the curvature of the crack-tip. Theocaris and Andrianopoulos [27] consider that the radius of the curve, which is suitable for each criterion, must be, at least, equal to the elastic-plastic boundary, which, in general, is not circular. This is valid also for brittle materials because all 
materials present some kind of non-linearity in their stress-strain curves before fracture. Thus, we must define the elastic-plastic boundary before applying any fracture criteria. The need to introduce the elastic-plastic boundary as the limiting curve when evaluating each criterion can also be seen, if one accepts that crack propagation is the consequence of the transition of a generic elementary volume in the vicinity of the crack-tip, from the elastic to the fracture state by passing obligatorily through a non-linear or plastic state. Since, stresses in each elementary volume depend strongly on the distance from the crack-tip, it is obvious that this distance is extremely important.

Hence, taking into account the singular character of stress components included in Eqs. (5) and (9) it is necessary to obtain the elastic-plastic boundary contour. For isotropic power-law hardening materials the plane-strain yield condition can be written [28] as

$$
\frac{\sigma_{e}^{2}}{3}=\tau_{e}^{2}=\left(\frac{\sigma_{x x}-\sigma_{y y}}{2}\right)^{2}+\sigma_{x y}^{2},
$$

while for plane stress it is

$$
\sigma_{e}^{2}=\sigma_{x x}^{2}+\sigma_{y y}^{2}-\sigma_{x x} \sigma_{y y}+3 \sigma_{x y}^{2},
$$

where $\sigma_{e}$ is the generalized effective tensile stress, $\tau_{e}$ is the generalized effective shear stress. Replacing $\sigma_{e}$ in Eqs. (13) and (14) by the yield stress $\sigma_{0}$ and substituting Eqs. (1) into it, one can determine the elastic-plastic boundary around the crack tip.

Calculations for the $\max \sigma_{\theta \theta}$ and the $\max \tau_{r \theta}$ criteria, modified so that the influence of the non-singular (second) term in the expression of stresses be taken into account. Behavior of the non-singular term $T$ as a function of the crack angle $\beta$ and the elastic mixity parameter $M_{E}$ are shown in Fig. 2 for different biaxial ratio $\eta$ and fixed value of normalized nominal stress $\bar{\sigma}=\sigma_{y n} / \sigma_{0}=0$.5. It is clear that the same value of the $T$-term can be obtained by various combinations of the crack angle and the biaxial ratio. Our numerical results (Fig. 3) for each criterion are given for three types of the stressed state: uniaxial tension $(\eta=0)$, biaxial tension $(\eta=0.5)$ and equibiaxial tension-compression $(\eta=-1)$.

It is interesting first to point out in Fig. 3 the differences between the values of $\theta^{*}$ corresponding to each criterion under pure shear (pure Mode II) loading conditions, i.e., $\eta=-1$ and $\beta=45^{\circ}$. Indeed, the maximum tangential stress criterion gives the value of $\theta^{*}=76^{\circ}$ for plane strain and $\theta^{*}=73^{\circ}$ for plane stress, while the maximum shear stress criterion predicts $\theta^{*}=0$. These differences in the $\theta^{*}$-values relate to the different dominant fracture mechanisms, lying in the basis of each criterion. Furthermore, it should be kept in mind that influence of orientation of the crack $\beta$ and the mode of biaxiality in loading of the plate $\eta$ on the direction $\theta^{*}$ of crack growth can be directly specified by the elastic mode 
mixity parameter $M_{E}$ with help of Eq. (3). Thus, using any fracture criterion, in particular, the maximum tangential stress and the maximum shear stress criteria in the form of Eqs. (6) and (10), the fracture initiation angle $\theta^{*}$ can be transformed into a function of the elastic mode mixity parameter $M_{E}$ for given values of both the biaxiality factor $\eta$ and the crack angle $\beta$ (Fig. 4). In other words, the crack propagation angle $\theta^{*}$ is defined in terms of the tensile and shear stresses at the crack tip vicinity as a function of the elastic far-field mixity parameter $M_{E}$, i.e., $\theta^{*}=f\left(M_{E}\right.$, criterion $)$. Note that, at the same values of $\eta$ and $\beta$, different criteria will predict different values of $\theta^{*}$. Besides, as it can be seen in Figs. 3 and 4 there is strong dependence for both criteria on the non-singular term. The results which are shown in Figs. 3 and 4 by solid lines are related to constant value of the core region radius $r / a=0.01$ in singular solutions (6) and (10) while the dashed lines represent the crack growth direction criteria when the crack distance is defined as elastic-plastic boundary contour $r_{p} / a$. From the point of view of the elastic-plastic analysis the use of the plastic zone boundary is preferable.
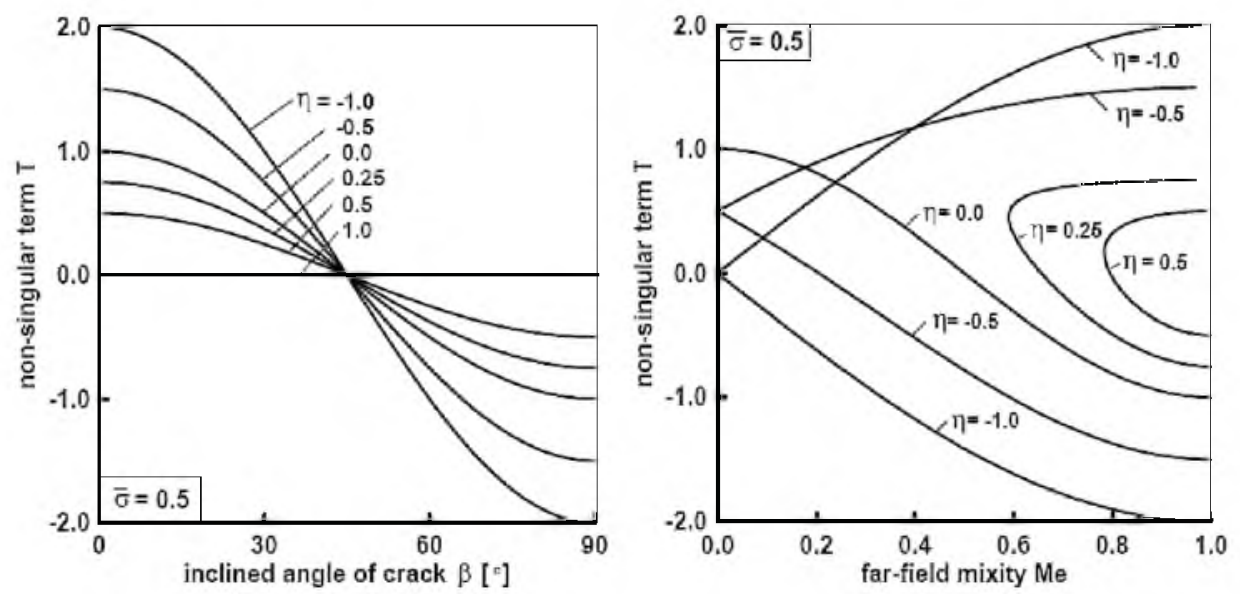

Fig. 2. Non-singular term $T$ versus crack angle $\beta$ and elastic mixity parameter $M_{E}$ under biaxial loading.

Small-Scale Yielding. Here we briefly discuss the boundary conditions for symmetric pure Mode I, anti-symmetric pure Mode II and mixed mode stress fields.

Mode I Crack-Tip Field (Tensile Crack). We first examine the Mode I crack-tip stress field for power-law hardening materials. The stress distribution of the Mode I plane-strain near-tip field under small-scale yielding conditions was presented in $[16,17]$. The stress-free boundary on the upper and lower faces of the crack requires that $\sigma_{r \theta}=\sigma_{\theta \theta}=0$ at $\theta=-180^{\circ}$ and $180^{\circ}$. For the symmetric Mode I stress field, we consider the case where $\sigma_{r r}>0$ on the stress-free crack faces. In front of the crack tip (the macrocrack growth direction), the shear stress $\sigma_{r \theta}$ at $\theta=0$ must vanish, while the normal stresses $\sigma_{r r}$ and $\sigma_{\theta \theta}$ have a local minimum and maximum, respectively for the symmetric Mode I stress field. 

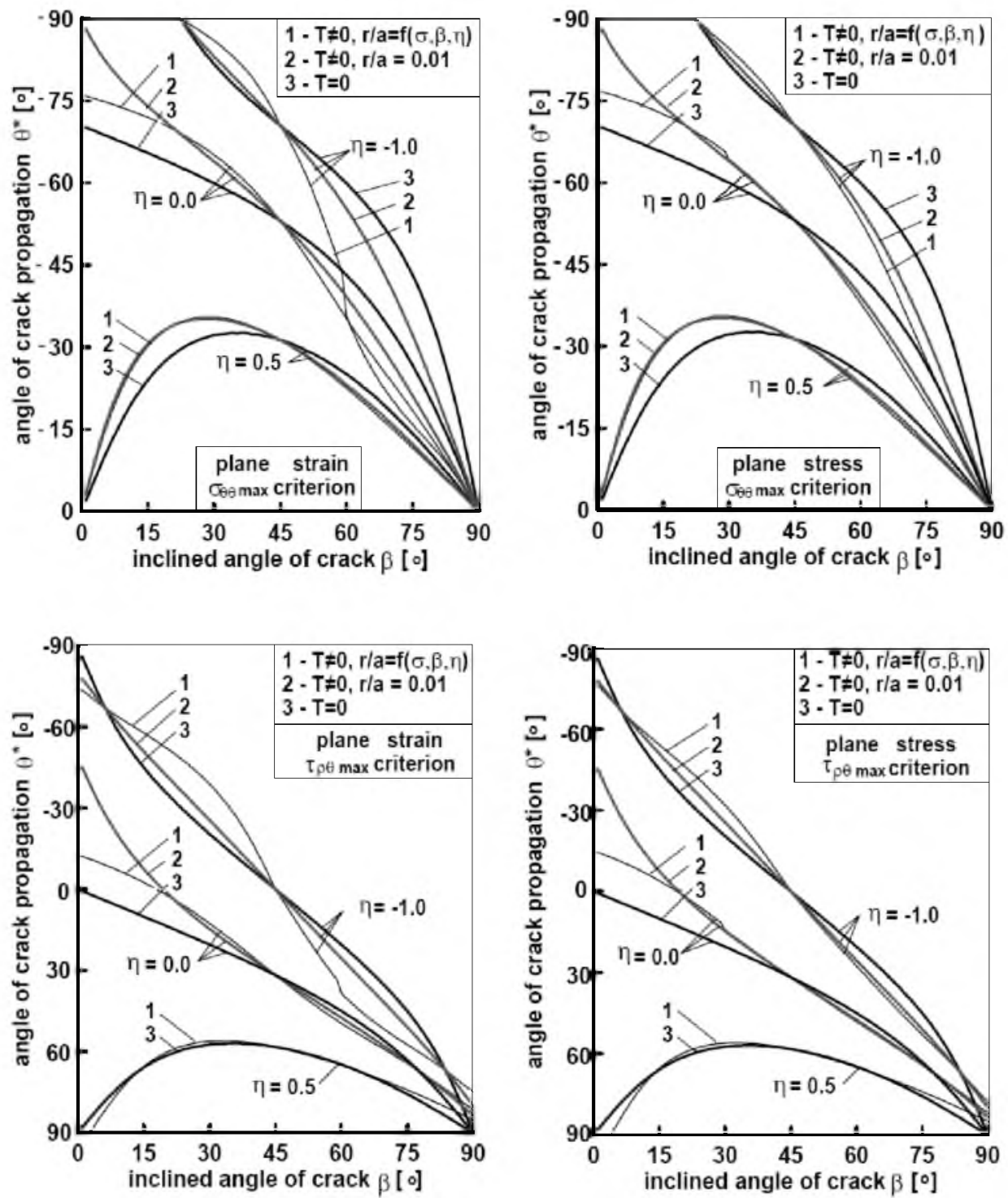

Fig. 3. Directions of initial crack extension $\theta^{*}$ according to the maximum tangential stress and the maximum shear stress criteria.

Mode II Crack-Tip Field (Shear Crack). Now we examine the antisymmetric Mode II stress field. The stress distribution of the Mode II plane-strain small-scale yielding conditions for strain-hardening materials was presented in $[15,16]$.

As for Mode I solution, the stress-free boundary conditions on the crack faces require that $\sigma_{r \theta}=\sigma_{\theta \theta}=0$ at $\theta=-180^{\circ}$ and $180^{\circ}$. We consider the loading conditions which produce the anti-symmetric Mode II stress field near the crack tip with $\sigma_{r r}>0$ at $\theta=-180^{\circ}$ and $\sigma_{r r}<0$ at $\theta=180^{\circ}$. Directly ahead of the crack tip $(\theta=0)$, the normal stresses $\sigma_{r r}$ and $\sigma_{\theta \theta}$ should vanish, while the shear stress $\sigma_{r \theta}$ has a local maximum for the anti-symmetric Mode II stress field. 

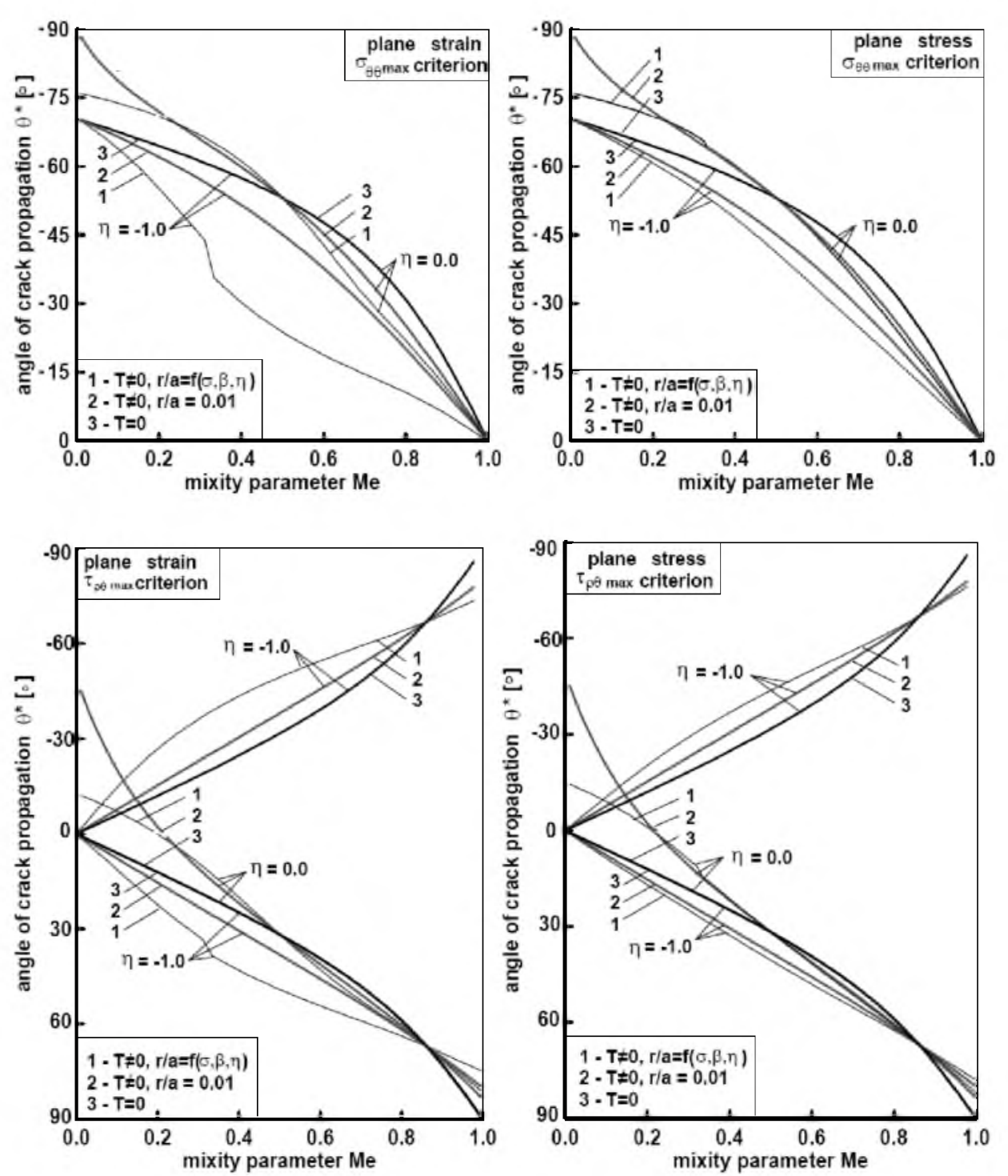

Fig. 4. Relations between $\theta^{*}$ and $M_{E}$ based on the MTS and MSS criteria in the cases of constant core region radius $r / a=0.01$ and elastic-plastic boundary $r_{p} / a$ under uniaxial tension $(\eta=0)$ and equibiaxial tension-compression $(\eta=-1)$.

The following analytical results of the solution of the nonlinear compatibility equation attract our attention. From our analytical solutions for plane strain and plane stress conditions to be discussed later we find the Airy crack-tip stress function and their derivatives which are plotted in Fig. 5 for both the predominant shear crack (Fig. 5a and 5d) and tensile crack (Fig. 5b and 5e) loading conditions, respectively. As shown in Fig. 5a and $5 \mathrm{~d}$ the boundary conditions corresponding to the shear crack is given at point $\theta^{*}=0$, that is pure Mode II. On the other hand, the predominant loading related to the tensile crack is given at point $\theta^{*}=-76.7^{\circ}$ (plane strain) and $\theta^{*}=-73.3^{\circ}$ (plane stress) for $n=9$, as it shown 

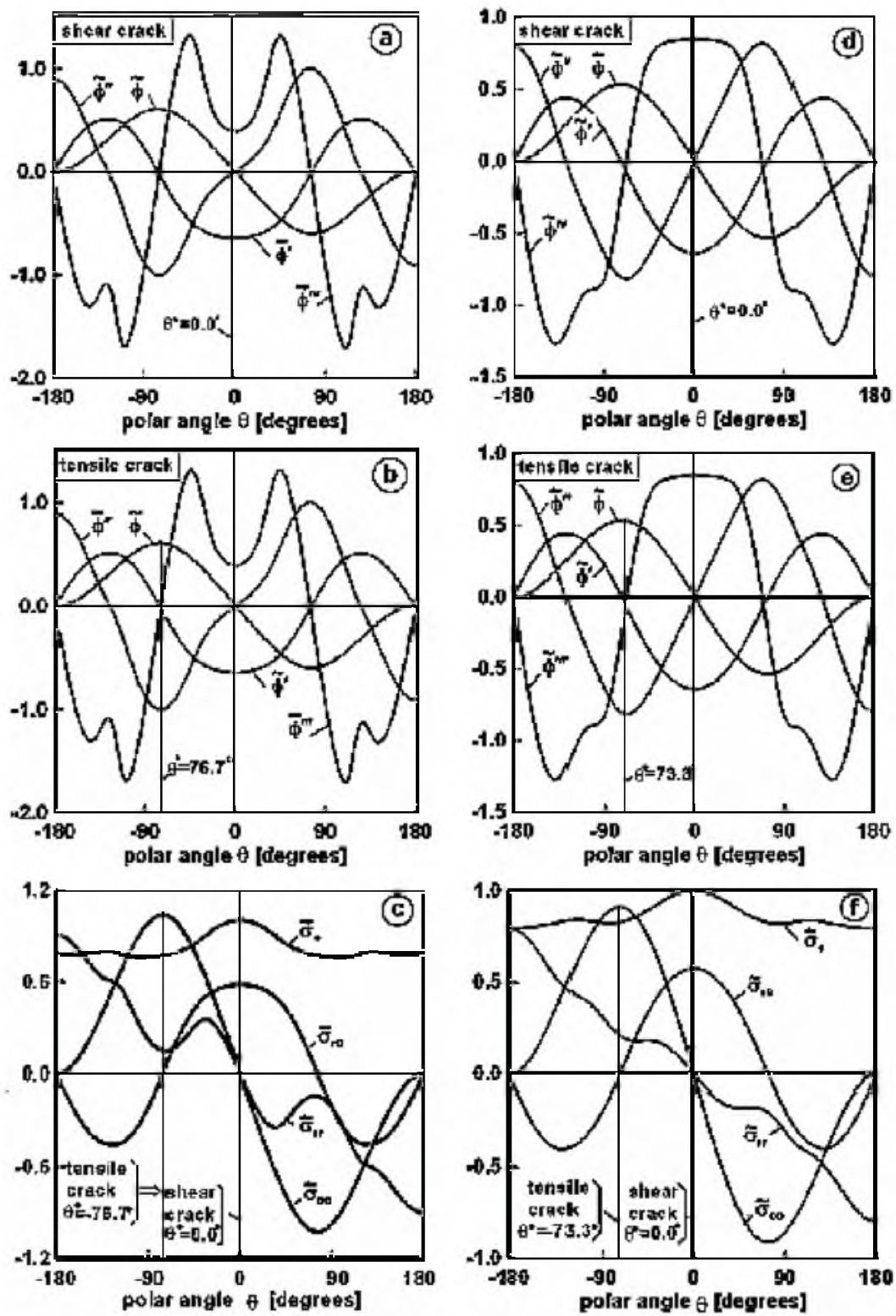

Fig. 5. Angular variation ( $a, b, d, e)$ of the Airy stress function and their derivatives $(c, f)$ of the crack-tip stress fields for pure Mode $I I, n=9,(\mathrm{a}, \mathrm{b}, \mathrm{c})-$ plane strain, (d, e, f) - plane stress.

in Fig. $5 \mathrm{~b}$ and 5 e. It is interesting to note that in this case when $\theta^{*}=-76.7^{\circ}$ the $\theta$-distributions of the Airy stress function and their derivatives in Fig. $5 \mathrm{~b}$ with respect to $\theta$ is similar to that of the plane strain pure Mode II crack-tip fields in Fig. 5a. The characteristics of the Airy stress function fields for each of the corresponding shear crack solution (Fig. 5a) and the tensile crack solution (Fig. 5b) are the same and both lead to the stress state that corresponds to the pure Mode II (Fig. 5c). Similar results for plane stress crack behavior are represented in Fig. 5d5f. The results shown in Fig. 5c are the crack-tip stresses for pure Mode II and agree well with the results $[15,16]$. As shown in Fig. 5c for plane strain, the 
general features of the crack-tip stress field are two equally possible crack growth directions, that are $\theta^{*}=0$ and $\theta^{*}=-76.7^{\circ}$, while for plane stress they are $\theta^{*}=0$ and $\theta^{*}=-73.3^{\circ}$.

Mixed-Mode Crack-Tip Field. On the both lower and upper crack faces, the stress-free condition requires that $\sigma_{r \theta}=\sigma_{\theta \theta}=0$ at $\theta= \pm 180^{\circ}$. We consider the loading condition which produces $\sigma_{r r}>0$ at $\theta=-180^{\circ}$. At this moment we will use, for instance, the Mode I stress field boundary conditions as the basis to construct the mixed Mode I and II stress field. We consider the loading conditions which alone would produce a Mode I crack-tip field. To generate a possible plane strain mixed mode solution we displace point $\theta=\theta^{*}$ (which specifies the boundary conditions and corresponds to the crack growth direction) on the $\theta$-axis to the left to a position of points $\theta^{*}=-17.1^{\circ}$ (Fig. 6b), $\theta^{*}=-39.9^{\circ}$ (Fig. 6c), $\theta^{*}=-57.2^{\circ}$ (Fig. 6d), $\theta^{*}=-68.7^{\circ}$ (Fig. 6e), and $\theta^{*}=-76.7^{\circ}$ (Fig. 6f). The displacement value depends upon the ratio of the Mode II load to the Mode I load. In Fig. 6 are shown our numerical results determined from singularity analysis, to be given later, concerning the stress fields for intermediate mixed mode state for strain-hardening exponent $n=9$. The point, which corresponds to the crack growth direction at the crack tip, consequently has to be moved from the position $\theta^{*}=0$ (pure Mode I) to the position $\theta^{*}=-76.7^{\circ}$ (pure Mode II), in order to cover the complete mixed mode range. Hence, the intermediate point $\theta=\theta^{*}$ of setting the boundary conditions governs of the stress fields under mixed mode loading. For each point, which is the crack growth direction and defined by angle $\theta=\theta^{*}$ (Fig. 6a-6f), the dimensionless stress component $\widetilde{\sigma}_{\theta \theta}\left(\theta^{*}\right)$ has the local maximum, $\widetilde{\sigma}_{r r}\left(\theta^{*}\right)$ has the local minimum, while $\widetilde{\sigma}_{r \theta}\left(\theta^{*}\right)$ is equal to zero, that corresponds to main postulates of both the maximum tangential stress and the local symmetry criteria. Since the stressed state at $\theta^{*}=0$ has to correspond to the pure Mode I (the tensile crack), while at $\theta^{*}=-76.7^{\circ}$ we have the pure Mode II (the shear crack) stressed state, we therefore expect that a change of the dominant fracture mechanism would occur. When point $\theta=\theta^{*}$ moves to the position of $\theta^{*}=-76.7^{\circ}$ where the normal stresses $\sigma_{r r}$ and $\sigma_{\theta \theta}$ are anti-symmetric with respect to the vertical line, the general crack-tip stress state reach the anti-symmetric pure Mode II crack-tip field. Our analytical results concerning the dimensionless stresses distributions under plane strain, which are presented in Fig. 6, in general, confirm the study of Shih [15].

In summary, by moving point (Fig. 6a-6f) from the position of $\theta^{*}=0$ to the position $\theta^{*}=-76.7^{\circ}$ for $n=9$, we can generate a complete range of mixed mode crack-tip field. The solutions for the stress field can be obtained for the corresponding crack growth direction criterion (or the dominant fracture mechanism). The study of this case suggests that, when point $\theta^{*}=\theta$ of application of the predominant tensile (shear) crack boundary conditions goes from pure Mode I (Mode II) to the mixed mode loading, there is indeed an intermediate stressed state where the crack tip field changes from the tensile (shear) crack dominant fracture mechanism to the shear (tensile) one. 

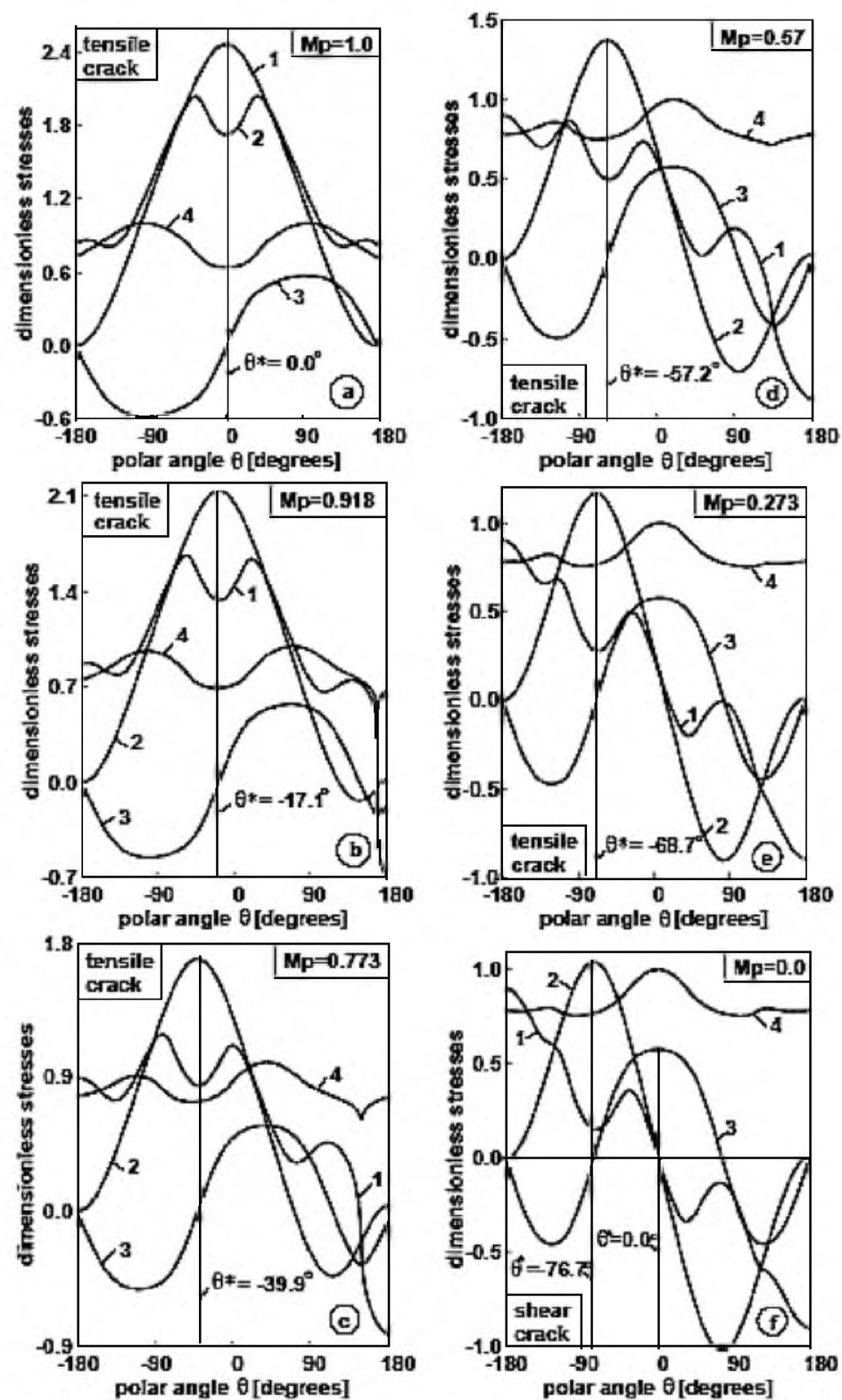

Fig. 6. The solutions of the mixed mode crack-tip stress field for tensile crack predominant loading conditions with $n=9$, (1) $\widetilde{\sigma}_{r r} ;$ (2) $\widetilde{\sigma}_{\theta \theta} ;$ (3) $\widetilde{\sigma}_{r \theta} ;$ (4) $\widetilde{\sigma}_{e}$

Then, taking into account the equation $M_{E}=f\left(\theta^{*}\right.$, criterion, dominant fracture mechanism), which obtained earlier, we can formulate a new scheme of mixed mode problem solution:

$$
\begin{aligned}
& \text { criterion } \theta^{*}=f(\hat{\beta}, \eta, \text { dominant fracture mechanism }) \\
& \downarrow \\
&(\beta, \eta) \rightarrow M_{E} \rightarrow \theta^{*} \rightarrow \widetilde{\sigma}_{i j} \rightarrow M_{P} .
\end{aligned}
$$


The relationship between $M_{E}$ and $M_{P}$ is now known in terms of the inclined crack angle $\beta$, biaxiality factor $\eta$, and the fracture initiation angle $\theta^{*}$. The elastic far-field and the plastic near-field can be regarded as completely identified for mixed-mode plane strain small-scale yielding. Thus, we found new method, which has enabled us to directly connect the near-field to the far-field throughout the fracture initiation angle.

Unlike the investigation [15], where the finite-element approach [29] was used to calculate the relationship between $M_{E}$ and $M_{P}$, in the present paper, the near-field mixity parameter $M_{P}$ was obtained directly from the compatibility equation solution as $\theta$-distribution of the dimensionless stresses $\widetilde{\sigma}_{\theta \theta}$ and $\widetilde{\sigma}_{r \theta}$ ranging from pure Mode I to pure Mode II and including an intermediate mixed mode fields. In particular, $M_{P}$ was obtained at $\theta=0$ when additional boundary condition in form of the crack growth direction was specified at $\theta=\theta^{*}$. This addition boundary condition, when we are solving the non-linear compatibility equation, is given a definite meaning by setting the maximum value of the $\theta$-variation of the tangential (shear) stress in an intermediate point, which is defined by the fracture initiation angle value $\theta^{*}$. Hence complete specification of the boundary conditions for the non-linear mixed mode problem includes both the stress-free boundary condition on the upper $\left(\theta=180^{\circ}\right)$ and lower $\left(\theta=-180^{\circ}\right)$ crack faces and the condition maximum tangential (shear) stress in the crack propagation direction $\left(\theta=\theta^{*}\right)$ depending on the fracture criterion.

Conclusions. The results of both numerical and analytical investigations show that each type of boundary conditions correspond to a definite crack growth direction criterion, in particular, in present paper, these are the maximum tangential and shear stress criteria. The satisfaction of one or another crack propagation criterion at $\theta=\theta^{*}$ implies that in this direction one or another dominant fracture mechanism will take place. Consequently, our approach makes it possible to obtain stress fields corresponding to one or another dominant fracture mechanisms. In the present work, these are the mechanisms that are discussed above and referred to as tensile and shear crack dominant fracture mechanisms.

Acknowledgements. Funding for this study was provided by the Russian Foundation for Basic Researches through grant 03-01-96233 and the Foundation of Academy of Sciences of Tatarstan Republic through grant 05-5.3-218/2003(f).

\section{Рез юм е}

На основі домінуючого механізму руйнування для оцінки поведінки матеріалу за маломасштабної текучості в області вістря тріщини сформульовано асимптотичні керуючі рівняння та їх граничні умови для випадків плоскої деформації і плоского напруженого стану. Рівняння базуються на деформаційній теорії пластичності зі степеневим зміцненням. Аналіз близько лежачих полів напружень виконано для критеріїв максимальних нормальних $\mathrm{i}$ дотичних напружень, повного діапазону змішаних форм деформування та різних рівнів показника зміцнення. Запропоновано нову схему розв'язку задач змішаних форм руйнування. Установлені співвідношення 
між визначальними пружними і пластичними параметрами змішаності представлено як функції виду критерію росту тріщини і показника деформаційного зміцнення матеріалу.

1. K. J. Miller, M. W. Brown, and J. R. Yates, "Some observations on mixed-mode fatigue behavior of polycrystalline metals," in: Mixed-Mode Crack Behavior, ASTM STP1359, Philadelphia (1999), pp. 229-257.

2. S. Aoki, K. Kishimoto, T. Yoshida, and M. Sakata, "A finite element study of the near crack tip deformation of a ductile material under mixed mode loading," J. Mech. Phys. Solids, 35, 431-455 (1987).

3. P. J. Budden, "The stress field near a blunting crack tip under mixed modes 1 and 2," J. Mech. Phys. Solids, 35, 457-478 (1987).

4. P. J. Budden, "The effect of blunting on the strain field at a crack tip under mixed modes 1 and 2," J. Mech. Phys. Solids, 36, 503-518 (1988).

5. V. K. Dhirendra and R. Narasimhan, "Mixed-mode steady-state crack growth in elastic-plastic solids," Eng. Fract. Mech., 59, 543-559 (1998).

6. Y. Arun Roy and R. Narasimhan, "A finite element investigation of the effect of crack tip constraint on hole growth under mode I and mixed mode loading," Int. J. Solid. Struct., 36, 1427-1447 (1999).

7. X. Gao and C. F. Shih, "A parametric study of mixed-mode I/III ductile fracture in tough materials under small scale yielding," Eng. Fract. Mech., 60, 407-420 (1998).

8. D. Bhattacharjee and J. F. Knott, "Ductile fracture in HY100 steel under mixed mode I mode II loading," Acta Metall. Mater., 42, 1747-1754 (1994).

9. C. Dalle Donne and H. Doker, "Plane stress crack resistance curves of an inclined crack under biaxial loading," in: Multiaxial Fatigue and Deformation Testing Techniques, ASTM STP 1280, Philadelphia (1997), pp. 243-263.

10. T. M. Maccagno and J. F. Knott, "The low temperature brittle fracture behavior of steel in mixed modes I and II," Eng. Fract. Mech., 38, 111-128 (1991).

11. V. N. Shlyannikov, "Modeling of crack growth by fracture damage zone," Theor. Appl. Fract. Mech., 25, 187-210 (1996).

12. V. N. Shlyannikov, "Mixed-mode static and fatigue crack growth in central notched and compact tension specimens," in: Mixed-Mode Crack Behavior, ASTM STP1359, Philadelphia (1999), pp. 279-294.

13. T. D. Swankie and D. J. Smith, "Low temperature mixed mode fracture of a pressure vessel steel subject to prior loading," Eng. Fract. Mech., 61, 387-405 (1998).

14. C. Dalle Donne, "The crack tip displacement vector approach to mixed-mode fracture," in: Mixed-Mode Crack Behavior, ASTM STP1359, Philadelphia (1999), pp. 21-40.

15. C. F. Shih, "Small-scale yielding analysis of mixed plane strain crack problem," in: Fracture Analysis, ASTM STP 560, Philadelphia (1974), pp.187-210. 
16. J. W. Hutchinson, "Singular behaviour at the end of a tensile crack in a hardening material," J. Mech. Phys. Solids, 16, 13-31 (1968).

17. J. R. Rice and G. F. Rosengren, "Plane strain deformation near a crack tip in power law hardening material," J. Mech. Phys. Solids, 16, 1-12 (1968).

18. J. Eftis, N. Subramonian, and H. Liebowitz, "Crack border stress and displacement equations revisited," Eng. Fract. Mech., 9, 189-210 (1977).

19. J. Eftis, N. Subramonian, and H. Liebowitz, "Biaxial load effects on the crack border elastic strain energy and strain energy rate," Eng. Fract. Mech., 9, 753-764 (1977).

20. J. Eftis and N. Subramonian, "The inclined crack under biaxial load," Eng. Fract. Mech., 10, 43-67 (1978).

21. R. V. Goldstein and R. L. Salganik, "Brittle fracture of solids with arbitrary cracks," Int. J. Fract., 10, 507-523 (1974).

22. B. A. Bilby and G. E. Cardew, "The crack with a kinked tip," Int. J. Fract., 11, 708-712 (1975).

23. F. Erdogan and G. C. Sih, "On the crack extension in plates under plane loading and transverse shear," Trans. ASME, J. Basic Eng., 85, 519-527 (1963).

24. A. C. Chrysakis, "Dependence of mixed mode crack propagation on the variation of $\sigma_{r}$ and $\tau_{r \theta}$," Eng. Fract. Mech., 24, 351-360 (1986).

25. A. C. Chrysakis, "Improvement of the $\max \sigma_{r}, \max \tau_{r \theta}$, and $\max \sigma_{1}$ criteria for mixed mode fracture," Eng. Fract. Mech., 26, 651-656 (1987).

26. J. G. Williams and P. D. Ewing, "Fracture under complex stress - the angled crack problem," Int. J. Fract. Mech., 8, 441-445 (1972).

27. P. S. Theocaris and N. P. Andrianopoulos, "The Mises elastic-plastic boundary as the core region in fracture criteria," Eng. Fract. Mech., 16, 425-432 (1982).

28. R. Hill, The Mathematical Theory of Plasticity, Oxford University Press, London (1950).

29. P. D. Hilton and J. W. Hutchinson, "Plastic stress intensity factors for cracked plates," Eng. Fract. Mech., 3, 445-451 (1971).

Received 06. 09. 2004 